\title{
CORRECTION
}

View Article Online

View Journal I View Issue

D) Check for updates

Cite this: J. Mater. Chem. B, 2020

8, 5547

DOI: $10.1039 /$ d0tb90088e

rsc.li/materials-b

\section{Correction: Facile synthesis of ultrathin Ni-MOF nanobelts for high-efficiency determination of glucose in human serum}

\author{
Xiao Xiao, Shasha Zheng, Xinran Li, Guangxun Zhang, Xiaotian Guo, Huaiguo Xue \\ and Huan Pang*
}

Correction for 'Facile synthesis of ultrathin Ni-MOF nanobelts for high-efficiency determination of glucose in human serum' by Xiao Xiao et al., J. Mater. Chem. B, 2017, 5, 5234-5239, DOI: 10.1039/C7TB00180K.

The authors want to clarify the correct details of the figures in the Supplementary Information of this manuscript. In the original manuscript, the details for Fig. S1 and S2 were incorrect. When processing the XRD and IR data, the authors misarranged the materials order, resulting in errors. The correct details for Fig. S1 and S2 are shown below:

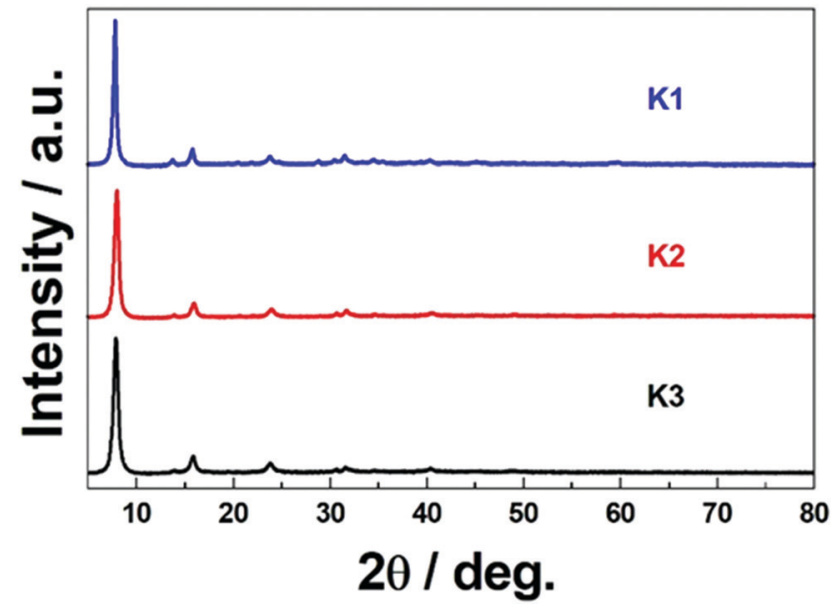

Fig. S1. XRD patterns of Ni-MOF materials. 


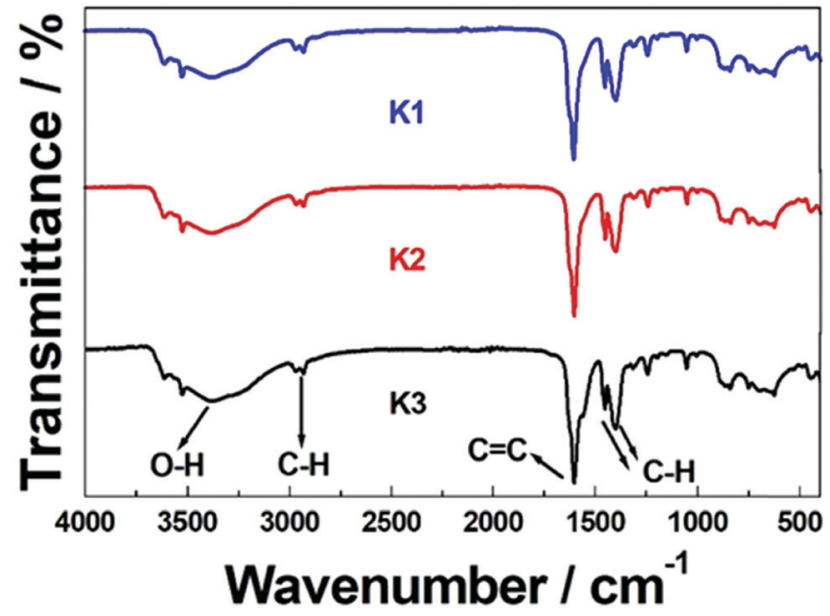

Fig. S2. IR spectrum of Ni-MOF materials.

These corrections do not affect the experimental conclusions.

The Royal Society of Chemistry apologises for these errors and any consequent inconvenience to authors and readers. 